\title{
Disproportionalities in Gifted and Talented Education Enrollment Rates: An Analysis of the U.S Civil Rights Data Collection Series
}

\author{
Allison List ${ }^{1}$ and Cass Dykeman \\ Oregon State University
}

This is the author's preprint. The copy of record is the following:

List, A. \& Dykeman, C. (2020) Disproportionalities in gifted and talented education enrollment rates: An analysis of the U.S. civil rights data collection series. Preventing School Failure: Alternative Education for Children and Youth. https://doi.org/10.1080/1045988X.2020.1837061

\begin{abstract}
Particular racial/ethnic and class groups remain underrepresented within gifted and talented education (GATE). However, students who are culturally and linguistically diverse (CLD) or gifted and disabled are also underrepresented but are often excluded from analysis. A cross-sectional design was to evaluate gifted enrollment data gathered by the Office for Civil Rights (OCR), using the Civil Rights Data Collection Series (CRDC). Proportional representation in GATE enrollment assessed students' race/ethnicity, English Language Learner (ELL) status, and disability status under the Individuals with Disabilities Education Act (IDEA). A one-sample $z$ test of proportions rendered statistically significant disproportionality across all groups evaluated. Results indicate the issue driving disproportionality lies within the theory of intelligence used to measure giftedness in Western school systems and calls for correctly diagnosing the GATE systems' underlying inequities.
\end{abstract}

Keywords: GATE, disproportionality, fluid intelligence, twice-exceptional, ELL, CLD

\section{Introduction}

Charles is a homeless Black male with autism-but he is also a homeless Black male with autism who is gifted. Students like Charles are statistically less likely to be identified for gifted education; those who are diverse in terms of race, ability, and class also have decreased access to and participate less in gifted programs in the United States (Ford \& Grantham, 2003; Ford, Grantham, \& Whiting, 2008). Throughout much of American history, underrepresented groups have seen their abilities go un- or under-recognized (Card \& Giuliano, 2016; Morris, 2001).

Data demonstrate longstanding and consistent underrepresentation of certain racial and socioeconomic groups within gifted programs (Callahan, 2005; Ford et al., 2008; Yaluma \& Tyner, 2018). Yet, even as data from the federal government bear out this lack of proportion, only $2 \%$ of academic studies pertaining to gifted education have focused on culturally and linguistically diverse (CLD) students (Elhoweris, Mutua, Alsheikh, \& Holloway, 2005). While the literature regarding students who are low SES and gifted is well-established, research pertaining to these variables (i.e. CLD and socioeconomic status) most often report their data using descriptive rather than inferential statistics, leaving the field of gifted education unexplored in this way.

1. Correspondence concerning this article should be addressed to Allison List, Counseling Academic Unit, Oregon State University, lista@oregonstate.edu A Preprint - Version 1, 6-25-19. 
A review of GATE literature resulted in six key themes: (1) racial/ethnic differences, (2) CLD, (3) low SES, (4) twice-exceptionality, (5) identification methods, and (6) retention. The research questions guiding this study will follow this review.

Enrollment disproportionalities exist across students' racial backgrounds. Callahan (2005) reported that Black and Hispanic students were less than half as likely to take part in gifted programs; so, too, were Native Alaskan and American Indian students profoundly underrepresented. Students who are Black, Hispanic, and American Indian have, in fact, been annually underrepresented in gifted education programs by at least $40 \%$ (Ford et al., 2008). Results from a recent meta-analysis of gifted studies, from 2002 to 2015, showed that Black, Hispanic, and American Indian students were about one third as likely to be identified for gifted education as were their White and Asian counterparts (Hodges, Tay, Maeda, \& Gentry, 2018). Grissom and Redding (2015) found that, for example, when compared to their White peers, Black students were $66 \%$ less likely to be identified for gifted programs. Yaluma and Tyner (2018) offered more in this regard, finding that, among schools with gifted programs around the nation, Black students were $15 \%$ of the total student population but only $10 \%$ of the enrolled gifted population. Meanwhile, Hispanic students were $27.6 \%$ of the total student population but only $20.8 \%$ of the enrolled gifted population.

Disproportionality rates for CLD students mirror those for students of color. Designated as ELLs by the U.S. Department of Education, CLD students can be distinguished by racial/ethnic minorities, language, and social class standing when compared to mainstream culture (Terry \& Irving, 2010). Students who are ELLs typically have not participated in gifted education. The ORC (2014) reported an overall gifted enrollment of $2.8 \%$ for
ELLs in the United States. The 2014-2015 State of the States in Gifted Education report listed 12 states that counted ELL gifted populations of $1 \%$ or under (NAGC, 2015), with Colorado reporting the highest rate, at $4.5 \%$ (NAGC). These data underscore the disproportionality in participation rates across groups, with scholars attending to larger demographic subgroups. Still, the literature on ELLs is rather limited.

Similar to race/ethnicity and CLD status, students living in poverty are underrepresented in gifted programs. This disproportionality exists even though, as Suitts (2015) found, low-income families constituted $51 \%$ of the student population. The 2014-2015 State of the States in Gifted Education report showed that rates of gifted enrollment for low SES students ranged from $1 \%$ to $38.9 \%$ across the 14 states that provided data (NAGC, 2015). Finally, Callahan (2005) noted that the National Education Longitudinal Study (NELS) pointed to only $9 \%$ of all gifted students coming from lowincome families.

Another area of disproportionality appears with students deemed twice-exceptional, or those who are gifted but who also have a disability. Twice-exceptional students can be identified in federal data sets under the IDEA designation, and they are rarely present in gifted programs. The 2013-2014 CRDC results indicated that students qualified under IDEA amounted to only $2.4 \%$ of gifted program enrollment in the United States (OCR, 2014). According to the 2014-2015 State of the States in Gifted Education report, rates for twice-exceptional students ranged from .1\% to $6 \%$ across the 15 states reporting data (NAGC, 2015). In a study examining twice-exceptionality in students living in Mississippi, those with speech and language delays - but who were still deemed gifted - made up only $1.5 \%$ of the identified gifted population (Karnes \& Bisland, 2004). This percentage was the largest of those considered twice-exceptional; those who were learning disabled 
and identified as gifted were the second largest group, registering at .5\% (Karnes \& Bisland).

Processes that lead to the identification of candidates for GATE programming have been notes as one key cause for such disproportionality rates (Maddocks, 2018). Grissom and Redding (2015) showed that identification methods have little to do with a student's intellectual abilityand, even more, that the classroom teacher's alignment or misalignment of race played a key role affecting student identification in the case of teacher referrals. A nonverbal screening option is the Cognitive Abilities Test (CogAT), The most recent literature examining the relationship between underrepresented populations and the CogAT found that group differences were not eliminated by using a universal screener such as the CogAT (Carman, Walther, \& Bartsch, 2018). Universal screeners are strongly encouraged, because all students are tested within a chosen grade level (Card \& Giuliano, 2016; Yaluma \& Tyner, 2018), therefore, in theory, increasing opportunity. Still, this method can also lead to disproportionalities (Carman et al.).

As challenging as recruitment is for underrepresented populations, professionals also struggle to retain students who end up enrolling in gifted programs. Data tracking student retention is not readily available (Ford, 1998; Ford et al., 2008); national retention rates are difficult to determine because available data track only enrollment rather than gifted program completion (Ford; Ford et al.). Especially in the case of CLD students, retention could be affected by recruitment - which is to say, CLD students might be concerned about fitting in and experiencing camaraderie with White peers and teachers, perhaps making the students less inclined to participate.

Given the aforenoted, two research questions were promulgated to guide the present study. The first question was: In terms of GATE program enrollment, do disproportionalities exist in student populations according to race/ethnicity, IDEA status, and ELL status? And the second question was: When considering GATE program enrollment, what is the ranking of U.S. states in terms of their disproportionalities with respect to race/ethnicity?

\section{Method}

\section{Design}

This study employed a cross-sectional observational design using archival (i.e., preexisting) data (Mann, 2003). The examination of gifted program enrollment attended to variables of race/ethnicity (binominal), disability status (binomial), and ELL status (binomial). Power analyses were not conducted, because the data contained the entire population.

\section{Participants}

Data were obtained from a publicly shared file within the 2015-2016 CRDC series. All participants were public school students within the United States.

\section{Measures}

GATE enrollment status. Program enrollment was dummy coded as 0 for $N o$ and 1 for Yes.

Disability status. Students designated with a disability under IDEA were coded as 0 for does not have a disability and 1 for has a disability.

Race/ethnicity status. Race was divided into two groups, with 0 representing historically underrepresented (i.e., Black, Hispanic, Indigenous, multi-racial, Pacific Islander) and 1 standing for historically overrepresented (i.e., Asian and White). 
ELL status. English Language Learners were coded as 0 for no ELL status and 1 for ELL status.

Total population disabilities proportion $\left(\boldsymbol{p}_{0}\right)$. This is the proportion of students among the national population who are disabled.

\section{Sample GATE disabilities proportion}

$(\hat{p})$. This is the proportion of students who were both enrolled in GATE and disabled. The sample proportion was drawn from this group.

Total population race/ethnicity proportion $\left(p_{0}\right)$. This is the proportion of students among the national population by race/ethnicity.

\section{Sample GATE race/ethnicity} proportions $(\hat{p})$. This is the proportion of students, by race/ethnicity, who enrolled in GATE. The sample proportion was drawn from students within over- and underrepresented racial groups who enrolled in GATE programs.

\section{Total population ELL status} proportion $\left(\boldsymbol{p}_{0}\right)$. This is the proportion of students among the national population who are ELL status.

\section{Sample GATE ELL status proportion}

$(\hat{p})$. This is the proportion of students who enrolled in GATE and who are ELL status. The sample proportion was drawn from students who both enrolled in GATE programs and were ELL status.

\section{Data Analysis}

The first research question measured proportional differences between GATE students and the entire student population. All three demographic variables were binomial. A one-sample $z$ test of proportions allows researchers to analyze an observed binomial variable (i.e., $\hat{p}$ ) against a known population proportion (i.e., $p_{0}$ ) (Daly \& Bourke, 2008). The significance level for all analyses, including inferential ones, was set at .05. The second research question relied on the Rae Index to quantify the size of each state's racial disproportionality, producing an index value. Descriptive statistics were then used to rank-order individual state racial disproportionality index values. Both research questions were computed using the statistical programming language, $R$, for their analyses.

\section{Results}

A one-sample $z$ test of proportions demonstrated proportional differences with respect to the first research question, rendering statistically significant results in terms of race/ethnicity, language status, and disability status. In the case of race/ethnicity, the results for historically underrepresented racial groups were: $p_{0}=.47, \hat{p}=$ .31, $n=1,034,427, p=<.05$., while the results for ELL status were: $p_{0}=.10, \hat{p}=.02, n=90,998, p=$ $<.05$. Finally, the results for IDEA designation were: $p_{0}=.12, \hat{p}=.02, n=88,063$, and $p=<.05$.

The second research question relied on the Rae Index to quantify the size of the racial disproportionality within each state by measuring the absolute deviation between expected and observed proportions. Rae Index scores closer to 0 have smaller differences between expected and observed proportions, and scores closer to 1 have larger differences. Index scores among states were then ranked from smallest to largest - that is, from least disproportionate to most disproportionate. See Table 1 for individual state rankings.

\section{Discussion}

In terms of race/ethnicity, there are three possible explanations for the above results. First, states and school districts lack consistent policies for identifying students for gifted programs 
(NAGC, 2015). Second, racial disproportionalities in these data could be a function of cultural bias in the measures adopted to identify gifted status. While certain nonverbal measures, such as the Raven Standard Progressive Matrices (RAVEN, 1941), the NNAT, and the CogAT, have been shown to reduce racial differences in gifted identification, entirely culture-neutral tests do not exist (Sternberg, 2018). Third, it could be that giftedness, which is based on fluid intelligence (i.e., Gf), is culture-bound.

While these arguments are all plausible, the third explanation is the most logical because a culture-bound theory of intelligence influences societal conceptions of giftedness and shapes related programming. Although there are various types of intelligence, $\mathrm{G} f$ is the one mostly commonly used to identify giftedness in children (McBee, Peters, \& Miller, 2016). In essence, $\mathrm{G} f$ is the ability to solve problems; however, learning how to solve problems, as well as understanding which problems are worth solving, are skills defined differently across cultures (Cocodia, 2014; Sternberg, 2018).

The upshot here is that, despite profound differences in cultural and racial backgrounds, children living in the United States are screened for giftedness based on how well they have adapted to Western culture and by the degree to which their achievements are consistent with Western values. The race/ethnicity and ELL variables show an unavoidable explanatory overlap in terms of their results. While both variables have unique characteristics, we cannot deny the depth and strength of the shared cultural component that sets these groups apart from mainstream Western culture.

These designations invite us to consider three shared explanations as well as two additional explanations not yet considered. The first shared explanation addresses inconsistencies in identification measures existing across states and school districts (NAGC, 2015). The second shared explanation posits that gifted identification measures contain cultural bias privileging mainstream Western culture (Cocodia, 2014; Ford et al., 2008; Naglieri \& Ford, 2003; Sternberg, 2018). Selected nonverbal batteries putatively assess the potential giftedness of ELL students, but Lohman, Korb, and Lakin (2012) found that the three most common instruments (CogAT, NNAT, and RAVEN) insufficiently assessed ELL students. Significantly then, inadequate attention discourages the adoption of nonverbal measures as best practices in gifted assessments for students who are linguistically diverse. A third and final shared argument targets the culture-bound theory of intelligence in which gifted identification is rooted (Cocodia; Sternberg).

Of the two explanations not yet considered, the first pertains to the administration of assessments. Assessing student performance by snapshot testing, where a test is administered only once, fails to address the needs of ELL students (National Council of Teachers of English, 2008), especially considering the level of familiarity that speakers of limited English have with standardized testing (Sternberg, 2018). The second explanation not yet considered focuses on an ELL student's experience with culture shock. The complicated relationship of external factors igniting culture shock can mask academic abilities, often resulting in the overrepresentation of ELL students in Special Education programs (Brown, 2004). As such, culture shock could also be responsible for the underrepresentation of ELL students in gifted programming.

The most logical explanation is, again, a culture-bound theory of intelligence. Intelligence is a measure of adaptability, although acquiring adaptive skills is specific to the context of our environment (Sternberg, 2018). While the form of intelligence used to measure giftedness in Western culture (i.e., $\mathrm{G} f$ ) is a measure of adaptability, conventional cognitive testing does not identify 
skills that ELL students have acquired in their countries of origin (Sternberg). Arguments that target testing and assessment are, therefore, somewhat misplaced; looking at the results and consequences more critically indicates the problem is culture-bound.

In terms of IDEA designation, four possible explanations warrant consideration. The first argument states that stereotypes of giftedness have diminished opportunity within our educational system. Research encouraging a more complex and dynamic conception of giftedness is prevalent, but a combination of teacher training that is insufficiently attentive to diverse learners and the lasting influences of Terman's (1925) studies encourages educators to conceive of gifted students as needing to excel in all academic areas and as demonstrating great social and moral development (Bianco \& Leech, 2010). The second argument involves perceptions that special education teachers have toward ability. Special education training calls for identifying deficits and employing intervention; thus, teachers view the ability of a student with an IDEA designation through a lens of remediation rather than through a lens of potentiality - potentiality that could, instead, emphasize the student's strengths (Bianco \& Leech; Pfeiffer, 2009). Not surprisingly, given this tendency, Bianco and Leech showed that special education teachers have the lowest referral rates to gifted education programs.

The third argument suggests that the masking effect limits opportunity for students who are disabled and gifted (Bianco \& Leech, 2010; Maddocks, 2018; Pfeiffer, 2009; Silverman, 2009). Students who are twice-exceptional, in terms of giftedness and disability, are additionally challenged because the interaction of the students' two spheres of exceptionality can complicate their performance in testing, making them appear to be average (Bianco \& Leech; Maddocks). The fourth explanation states that no clear process exists to identify, as gifted, students with a disability
(Lovett \& Sparks, 2013; Maddocks). Scholars and practitioners differ over the classification of twiceexceptionality (Lovett \& Sparks; Maddocks), and this lack of consensus has resulted in inconsistent selection and administration of gifted measures used for identification, while also contributing to concerns over validity (Lovett \& Sparks).

Among these possibilities, the most logical is the fourth explanation, pointing to the lack of a clear process for identifying twice-exceptionality. By nature, a process describes how something is done, while striving to make tasks more efficient, especially in situations involving large volumes. Any means by which a school district goes about identifying giftedness in students is a process; therefore, if identification processes differ across districts and states, they tend to become counterproductive, especially for student groups who are vulnerable populations and who exist in small percentages in gifted programs. Due to the inconsistent operationalization carried out by scholars, research has failed to generate valid forms of measurement and criteria for identifying twiceexceptional students. Without a clear recognition process and designated best practices, identification rates for this group will remain disproportionate.

In terms of the second research question, the Rae Index quantified the size of racial disproportionality existing within states. The scores were then rank-ordered from smallest to largest disproportionality, nationwide on a $0-1$ scale. Variability among index scores can be explained by considering the population proportion by race present in individual states. For example, the two states with the highest scores had a higher $p_{0}$ value (i.e., proportion of students expected to enroll) based on higher racial proportions of students in the total populations within their states. Yet the $\hat{p}$ value (i.e., proportion of students who actually enrolled) resulted in half of the expected proportion, creating a larger disproportionality size. Therefore, variability in racial disproportionality 
sizes among state rankings are driven by the size of the expected population proportion.

This study contains two limitations of note. First, not every state made its identification procedures available. While an analysis of relationships among identification procedures and disproportionality was not the purpose of this study, having identification measures employed by each state could inform future research on enrollment-related equity gaps. Second, caution is necessary when interpreting the IDEA results, as specific disabilities associated with giftedness were not available. It is important to note, too, that while there are currently 13 disability categories under IDEA, the literature on twice-exceptionality typically focuses only on the three most often associated with giftedness: specific learning disabilities, autism, and other health impairments (Pereira, Knotts, \& Roberts, 2015). Due to data restrictions, inferences extend only as far as the direct finding of underrepresentation, in gifted education, of students who are twice-exceptional.

While most work in the field points to assessments and identification processes as the causes of disproportionality, the present study offers something different. Scholars and social justice advocates in gifted education have charged that deficit thinking operates as a gatekeeper for gifted programs, but this research finds the roots of the problem reach much deeper than previously realized, demanding a response that goes beyond simply multicultural training and continuing education. Deficit thinking is grounded in historical misperceptions of and errant beliefs about race, but this study posits that deficit thinking actually transcends race - suggesting that such bias can also affect CLD students. Future research should, therefore, focus on the culture-bound nature of the theory of intelligence (i.e., fluid intelligence) on which gifted education is based. A mixed-method study surveying the prevalence of this theory of intelligence and its influence on curriculum in training programs, as well as a qualitative analysis of the leadership in such programs, would, for example, better reveal how, when, and why constructions of "giftedness" emerged and, even more, how they have been maintained. Thereby showing that a continuation of current gifted practices is, indeed, putting the word "GATE" in gatekeeping.

\section{References}

Bianco, M., \& Leech, N. L. (2010). Twiceexceptional learners: Effects of teacher preparation and disability labels on gifted referrals. Teacher Education and Special Education, 33, 319-334. https://doi.org/10.1177/0888406409356392

Brown, C. L. (2004). Reducing the over-referral of culturally and linguistically diverse students (CLD) for language disabilities. NABE Journal of Research and Practice, 2, 225-243.

Callahan, C. M. (2005). Identifying gifted students from underrepresented populations. Theory Into Practice, 44, 98-104. http://dx.doi.org/10.1207/s15430421tip440 $2 \_4$

Card, D., \& Giuliano, L. (2016). Universal screening increases the representation of low-income and minority students in gifted education. Proceedings of the National Academy of Sciences, 113(48), 1367813683. https://doi.org/10.1073/pnas.1605043113

Carman, C. A., Walther, C. A., \& Bartsch, R. A. (2018). Using the Cognitive Abilities Test (CogAT) 7 nonverbal battery to identify the gifted/talented: An investigation of demographic effects and norming plans. Gifted Child Quarterly, 62, 193-209. https://doi.org/10.1177/0016986217752097

Cocodia, E. A. (2014). Cultural perceptions of human intelligence. Journal of Intelligence, 2, 180-196. https://doi.org/10.3390/jintelligence204018 0 
Daly, L., \& Bourke, G. J. (2008). Interpretation and uses of medical statistics. New York, NY: John Wiley \& Sons.

Elhoweris, H., Mutua, K., Alsheikh, N., \& Holloway, P. (2005). Effect of children's ethnicity on teachers' referral and recommendation decisions in gifted and talented programs. Remedial and Special Education, 26, 25-31.

https://doi.org/10.1177/0741932505026001 0401

Ford, D. Y. (1998). The underrepresentation of minority students in gifted education: Problems and promises in recruitment and retention. The Journal of Special Education, 32, 4-14. https://doi.org/10.1177/0022466998032001 02

Ford, D., Y., \& Grantham, T. C. (2003). Providing access for culturally diverse gifted students: From deficit to dynamic thinking. Theory Into Practice, 42, 217-225. https://doi.org/10.1207/s15430421tip4203_ 8

Ford, D. Y., Grantham, T. C., \& Whiting, G. W. (2008). Culturally and linguistically diverse students in gifted education: Recruitment and retention issues. Exceptional Children, 74, 289-306.

Grissom, J. A., \& Redding, C. (2015). Discretion and disproportionality: Explaining the underrepresentation of highachieving students of color in gifted programs. AERA Online, 2, 1-15. https://doi.org/10.1177/2332858415622175

Hodges, J., Tay, J., Maeda, Y., \& Gentry, M. (2018). A meta-analysis of gifted and talented identification practices. Gifted Child Quarterly, 62, 147-174. https://doi.org/10.1177/0016986217752107

Karnes, F. A., \& Shaunessy, E. (2004). Gifted students with disabilities: Are we finding them? Gifted Child Today, 27, 1621. https://doi.org/10.4219/gct2004-148
Lohman, D. F., Korb, K. A., \& Lakin, J. M. (2008). Identifying academically gifted English-language learners using nonverbal tests: A comparison of the Raven, NNAT, and CogAT. Gifted Child Quarterly, 52, 275-296. https://doi.org/10.1177/0016986208321808

Lovett, B. J., \& Sparks, R. L. (2013). The identification and performance of gifted students with learning disability diagnoses: A quantitative synthesis. Journal of Learning Disabilities, 46, 304-316. https://doi.org/10.1177/0022219411421810

Maddocks, D. L. (2018). The identification of students who are gifted and have a learning disability: A comparison of different diagnostic criteria. Gifted Child Quarterly, 62, 175-192. https://doi.org/10.1177/0016986217752096

Mann, C. J. (2003). Observational research methods. Research design II: cohort, cross sectional, and case-control studies. Emergency Medicine Journal, 20, 54-60. doi:10.1136/emj.20.1.54

McBee, M. T., Peters, S. J., \& Miller, E. M. (2016). The impact of the nomination stage on gifted program identification: A comprehensive psychometric analysis. Gifted Child Quarterly, 60, 258278. https://doi.org/10.1177/0016986216656256

Morris, J. E. (2001). African American students and gifted education: The politics of race and culture. Roeper Review, 24, 59-62. http://dx.doi.org/10.1080/02783190209554 130

Naglieri, J. A., \& Ford, D. Y. (2003). Addressing underrepresentation of gifted minority children using the Naglieri Nonverbal Ability Test (NNAT). Gifted Child Quarterly, 47, 155-160. https://doi.org/10.1177/0016986203047002 06

National Association for Gifted Children. (2015). State of the states in gifted 
education: Policy and practice data 2014-

2015. Washington, DC: Author.

Retrieved from

http://www.nagc.org/sites/default/files/ke

y\%20reports $/ 2014$

$2015 \% 20$ State $\% 20$ of $\% 20$ the $\% 20$ States $\% 20$ su

mmary.pdf

National Council for Teaching English. (2008).

English language learners. A Policy

Research Brief. Retrieved from

http://www.ncte.org/library/NCTEFiles/R

esources/PolicyResearch/ELLResea

rchBrief.pdf

Office for Civil Rights. (2014). Civil rights data

collection. Gifted and

talented, 2013-2014 [Data file]. Retrieved

from

https://ocrdata.ed.gov/StateNationalEstim

ations/Estimations_2013_14

Pereira, N., Knotts, J. D., \& Roberts, J. L. (2015).

Current status of twice-exceptional

students: A look at legislation and policy in the United States. Gifted and Talented

International, 30(1-2), 122-134.

https://doi.org/10.1080/15332276.2015.113

7463

Pfeiffer, S. I. (2009). The gifted: Clinical challenges for child psychiatry. Journal of the

American Academy of Child and

Adolescent Psychiatry, 48(8), 787-790. doi:

10.1097/CHI.0b013e3181aa039d

Raven, J. C. (1941). Standardization of progressive matrices, 1938. British Journal of

Medical Psychology, 19, 137-150.

https://doi.org/10.1111/j.2044-

8341.1941.tb00316.x

Silverman, L. K. (2009). The two-edged sword of compensation: How the gifted cope with learning disabilities. Gifted Education

International, 25, 115-130.

https://doi.org/10.1177/0261429409025002

03

Sternberg, R. J. (2018). Context-sensitive cognitive and educational testing.

Educational Psychology Review, 30, 857-

884. https://doi.org/10.1007/s10648-

017-9428-0

Suitts, S. (2015). A new majority research bulletin:

Low income students now a

majority in the nation's public schools.

Atlanta, GA: Southern Education

Foundation. Retrieved from

https://www.southerneducation.org/wp-

content/uploads/2019/02/New-Majority-

Update-Bulletin.pdf

Terman, L. M. (1925). Genetic studies of genius.

Mental and physical traits of a

thousand gifted children. Stanford, CA:

Stanford University Press.

Terry, N.P., \& Irving, M. A., (2010). Cultural and

linguistic diversity: Issues in

education. Special Education for All

Teachers, 5, 109-132.

U.S. Department of Education, National Center for Education Statistics. (2017).

Indicator 6 Elementary and Secondary

Enrollment. Retrieved from

https://nces.ed.gov/programs/raceindicator s/indicator_rbb.asp

Yaluma, A., \& Tyner, C. B. (2018). Is there a gifted gap? Gifted education in high-

poverty schools. Retrieved from https://edexcellence.net/publications/isthere-

a-gifted-gap 
Table 1

Racial Disproportionality in Gifted Enrollment by State

\begin{tabular}{|c|c|}
\hline State & $\begin{array}{c}\text { Rae } \\
\text { Index } \\
\text { Score } \\
(0-1)\end{array}$ \\
\hline New & 0.0132 \\
\hline Hampshire & \\
\hline Rhode Island & 0.0151 \\
\hline West Virginia & 0.0176 \\
\hline Maine & 0.0241 \\
\hline Massachusetts & 0.0329 \\
\hline Montana & 0.0454 \\
\hline Utah & 0.0475 \\
\hline North Dakota & 0.0575 \\
\hline Wyoming & 0.0757 \\
\hline Michigan & 0.0764 \\
\hline Arkansas & 0.081 \\
\hline Kentucky & 0.082 \\
\hline New York & 0.0831 \\
\hline Minnesota & 0.0896 \\
\hline Iowa & 0.0902 \\
\hline Missouri & 0.0913 \\
\hline Wisconsin & 0.0929 \\
\hline Pennsylvania & 0.0939 \\
\hline Indiana & 0.1052 \\
\hline Illinois & 0.1062 \\
\hline Oklahoma & 0.1111 \\
\hline Idaho & 0.1121 \\
\hline Ohio & 0.1155 \\
\hline Alaska & 0.1167 \\
\hline New Jersey & 0.1204 \\
\hline Kansas & 0.121 \\
\hline Oregon & 0.1296 \\
\hline Nebraska & 0.1313 \\
\hline Tennessee & 0.1372 \\
\hline Connecticut & 0.1431 \\
\hline Hawaii & 0.1529 \\
\hline Colorado & 0.1543 \\
\hline Virginia & 0.1554 \\
\hline
\end{tabular}




$\begin{array}{ll}\text { Maryland } & 0.1564 \\ \text { Washington } & 0.1567 \\ \text { Florida } & 0.1569 \\ \text { Texas } & 0.1601 \\ \text { California } & 0.1628 \\ \text { South Dakota } & 0.1671 \\ \text { Louisiana } & 0.1699 \\ \text { Nevada } & 0.177 \\ \text { Alabama } & 0.1917 \\ \text { Arizona } & 0.1964 \\ \text { South Carolina } & 0.2022 \\ \text { Mississippi } & 0.2065 \\ \text { New Mexico } & 0.2069 \\ \text { Delaware } & 0.2079 \\ \text { Georgia } & 0.2459 \\ \text { North Carolina } & 0.2516\end{array}$

